PETIR: Jurnal Pengkajian dan Penerapan Teknik Informatika Vol. 13, No. 1, Maret 2020, P-ISSN 1978-9262, E-ISSN 2655-5018 DOI: https://doi.org/10.33322/petir.v13i1.908

\title{
Penggunaan Global Contrast Saliency dan Histogram of Oriented Gradient Sebagai Fitur untuk Klasifikasi Jenis Hewan Mamalia
}

\author{
Yohannes $^{\text {; }}$ Muhammad Ezar Al Rivan ${ }^{2}$ \\ ${ }^{1,2}$ STMIK Global Informatika MDP \\ ${ }^{1}$ yohannesmasterous@mdp.ac.id \\ ${ }^{2}$ meedzhar@mdp.ac.id
}

\begin{abstract}
Mammal type can be classified based on the face. Every mammal's face has a different shape. Histogram of Oriented Gradient (HOG) used to get shape feature from mammal's face. Before this step, Global Contrast Saliency used to make images focused on an object. This process conducts to get better shape features. Then, classification using $k$-Nearest Neighbor (k-NN). Euclidean and cityblock distance with $k=3,5,7$ and 9 used in this study. The result shows cityblock distance with $k=9$ better than Euclidean distance for each $k$. Tiger is superior to others for all distances. Sheep is bad classified.
\end{abstract}

Keywords: Mammal, HOG, Global Contrast Saliency, $k-N N$

\begin{abstract}
ABSTRAK
Jenis mamalia dapat diklasifikasian berdasarkan bentuk wajah. Setiap mamalia memiliki bentuk wajah yang berbeda-beda. Metode Histogram of Oriented Gradient (HOG) digunakan untuk mengambil fitur bentuk dari citra wajah mamalia. Sebelum dilakukan ekstraksi fitur, metode Global Contrast Saliency digunakan untuk membuat citra terfokus pada objek. Hal ini dilakukan agar fitur bentuk menjadi lebih baik. Proses selanjutnya yaitu melakukan klasifikasi menggunakan k-Nearest Neighbor (k-NN). Distance yang digunakan yaitu euclidean dan cityblock dengan masing-masing nilai $k$ yaitu 3,5,7 dan 9. Hasil dari klasifikasi menunjukkan bahwa cityblock distance dengan $k=9$ lebih baik daripada eucidean distance untuk setiap $k$. Hewan yang diklasifikasikan paling baik yaitu harimau untuk semua jenis distance. Hewan yang tidak bisa diklasifikasikan dengan baik yaitu domba.
\end{abstract}

Kata kunci: Mammal, HOG, Global Contrast Saliency, $k$-NN 
PETIR: Jurnal Pengkajian dan Penerapan Teknik Informatika Vol. 13, No. 1, Maret 2020, P-ISSN 1978-9262, E-ISSN 2655-5018 DOI: https://doi.org/10.33322/petir.v13i1.908

\section{PENDAHULUAN}

Mamalia merupakan hewan bertulang belakang dan berkembang biak dengan cara melahirkan pada umumnya. Hewan mamalia memiliki banyak ciri dan karakteristik sehingga jenis mamalia sulit untuk dibedakan. Beberapa karakteristik pada hewan mamalia dapat menjadi fitur sebagai pembeda dalam klasifikasi. Citra jejak kaki yang merepresentasikan jumlah dan ukuran gumpalan bentuk kaki telah digunakan sebagai fitur pada klasifikasi jenis hewan [1]. Tidak hanya jejak kaki yang dapat menjadi fitur klasifikasi hewan, citra wajah hewan tampak depan juga mampu menjadi fitur utama. Citra wajah hewan tampak depan menjadi pilihan fitur klasifikasi karena dapat langsung mewakili dalam representasi hewan yang dimaksud. Pada penelitian [2], [3], [4], [5] citra wajah hewan telah digunakan sebagai fitur dalam klasifikasi hewan. Beberapa penggunaan metode ekstraksi fitur dan metode klasifikasi telah digunakan untuk klasifikasi hewan mamalia. Salah satu metode klasifikasi yang telah digunakan adalah $k$-Nearest Neigbor (k-NN). Metode k-NN telah banyak digunakan pada kasus klasifikasi seperti pada citra wajah [6], daun [7], batik [8], dan khususnya pada jenis hewan [3], [4], [9].

Global Contrast Saliency merupakan metode yang digunakan untuk mengambil wilayah dominan pada objek dalam sebuah citra. Dengan memperhitungkan perbedaan kontras warna pada setiap region-nya, metode ini mampu menghasilkan citra saliency dengan menampilkan wilayah objek yang lebih dominan [10]. Global Contrast Saliency dapat juga menjadi metode segmentasi objek karena mampu memisahkan objek dengan wilayah di luar objek pada sebuah citra. Metode Global Contrast Saliency digunakan untuk membuat wilayah objek agar lebih terlihat. Metode ekstraksi fitur yang digunakan pada penelitian ini adalah Histogram of Oriented Gradient (HOG). HOG merupakan fitur yang mampu digunakan sebagai fitur dalam klasifikasi dibandingkan dengan fitur lokal lainnya [2]. HOG digunakan sebagai fitur bentuk dari citra saliency yang dihasilkan dengan metode Global Contrast Saliency. Berdasarkan hal di atas, maka dilakukan klasifikasi wajah hewan mamalia tampak depan menggunakan metode ekstraksi fitur Global Contrast Saliency dan HOG dengan metode klasifikasi k-NN.

\section{METODE PENELITIAN}

Pada penelitian ini, dataset yang digunakan adalah LHI-Animal-Faces. Dataset ini merupakan data citra wajah hewan tampak depan yang terdiri dari 19 jenis hewan diantaranya 15 jenis hewan mamalia dan 4 jenis hewan unggas [11]. Sesuai dengan kebutuhan penelitian ini maka diambil 15 jenis hewan mamalia yang tiap jenisnya terdiri dari 60 citra dengan ukuran 150x150 pixel. Citra hewan mamalia tampak depan pada dataset dapat dilihat pada Gambar 1.

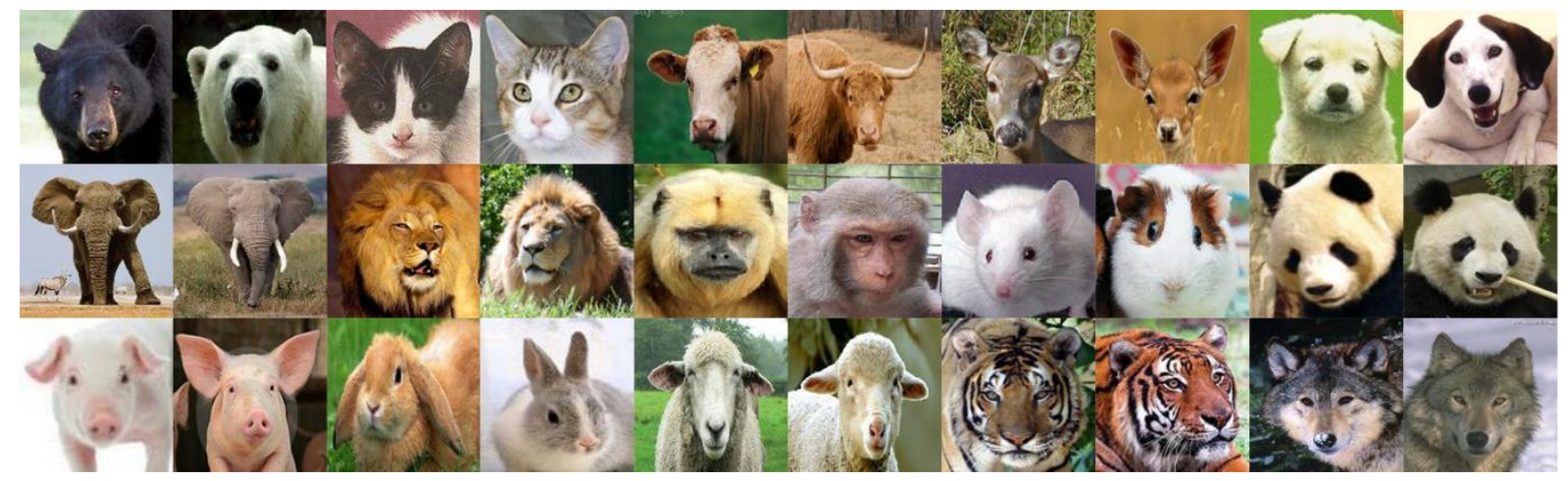

Gambar 1. Citra Wajah Hewan Mamalia Tampak Depan pada dataset LHI-Animal Faces [11] 
PETIR: Jurnal Pengkajian dan Penerapan Teknik Informatika Vol. 13, No. 1, Maret 2020, P-ISSN 1978-9262, E-ISSN 2655-5018 DOI: https://doi.org/10.33322/petir.v13i1.908

Tahapan yang dilakukan pada penelitian ini dimulai dengan membagi dataset hewan mamalia menjadi data latih (data training) dan data uji (data testing). Data latih dan data uji yang digunakan masing-masing terdiri dari 50 citra dan 10 citra pada setiap jenis hewan mamalia. Setiap citra baik pada data latih dan data uji dilakukan saliency map menggunakan global contrast based salient region untuk mengambil bagian wilayah yang dianggap penting yang pada sebuah citra. Selanjutnya, pada citra hasil saliency dilakukan ekstraksi fitur bentuk menggunakan histogram of oriented gradient (HOG). Semua fitur yang dihasilkan pada data latih dan data uji akan digunakan untuk proses klasifikasi menggunakan metode k-NN. Secara keseluruhan, tahapan metode yang diusulkan pada penelitian ini dapat dilihat pada Gambar 2.

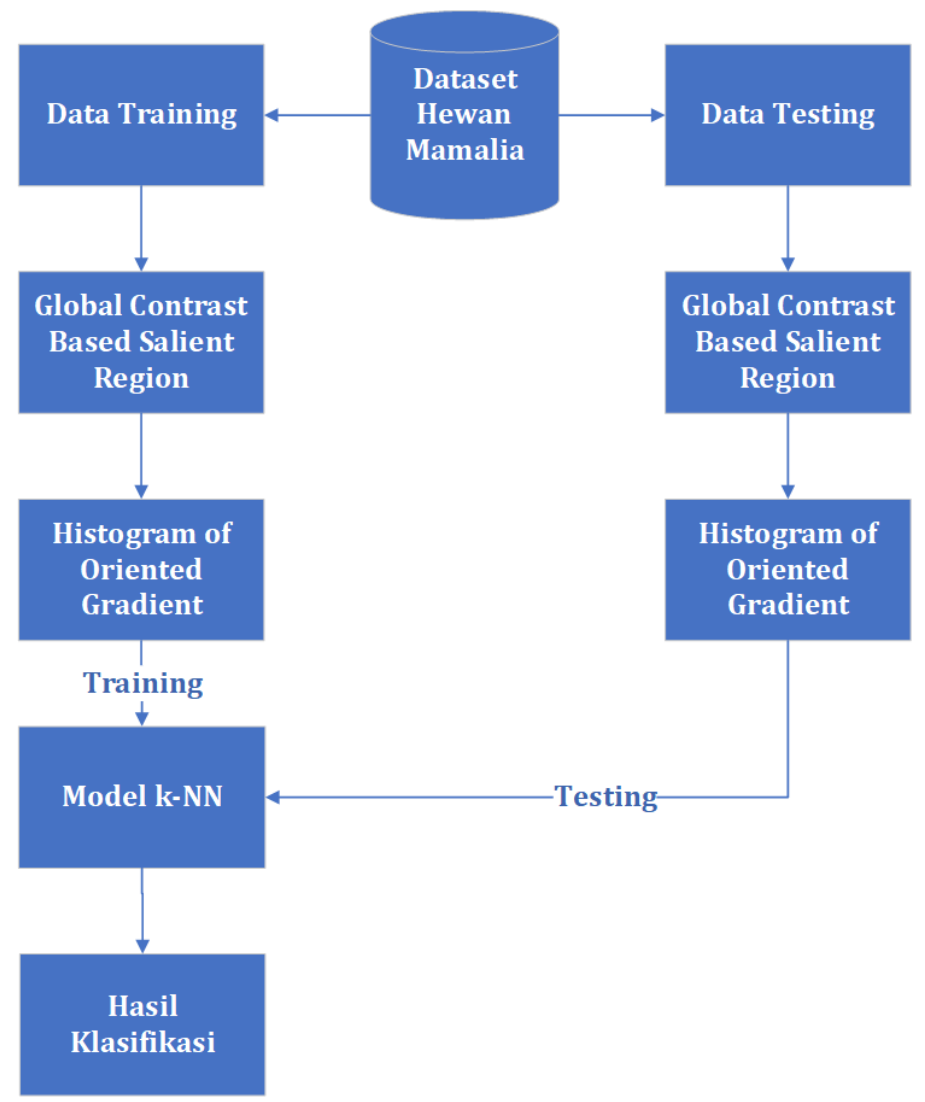

Gambar 2. Metode yang Diusulkan

Global Contrast Saliency merupakan metode saliency yang terbentuk dengan membandingkan kontras warna yang dominan pada setiap region dengan region lainnya yang tersegmentasi [10]. Tahapan metode global contrast saliency dapat dilihat pada Gambar 3. Saliency map yang dihasilkan dari global contrast saliency akan diekstraksi fiturnya menggunakan metode HOG. HOG digunakan sebagai fitur bentuk untuk citra saliency hewan mamalia tampak depan. HOG merupakan nilai gradien pixel yang dikelompokkan berdasarkan orientasi arah pada setiap bagian lokal objek citra. Alur metode HOG dapat dilihat pada Gambar 4. Selanjutnya, metode k-NN merupakan metode klasifikasi yang membandingkan fitur pada data uji dengan fitur yang paling mirip dengan data latih. Untuk menentukan hasil klasifikasi dengan metode k-NN adalah dengan menghitung jarak kedekatan (distance) antar data fitur. Terdapat berbagai cara untuk mengukur distance antara fitur data uji dengan fitur data latih, diantaranya menggunakan cityblock distance dan euclidean distance. Alur proses metode k-NN dapat dilihat pada Gambar 5. 
PETIR: Jurnal Pengkajian dan Penerapan Teknik Informatika Vol. 13, No. 1, Maret 2020, P-ISSN 1978-9262, E-ISSN 2655-5018 DOI: https://doi.org/10.33322/petir.v13i1.908

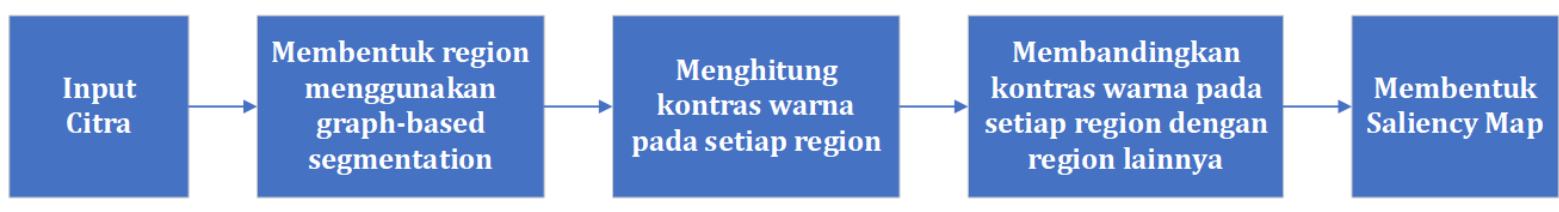

Gambar 3. Tahapan Metode Global Contrast Saliency [10]

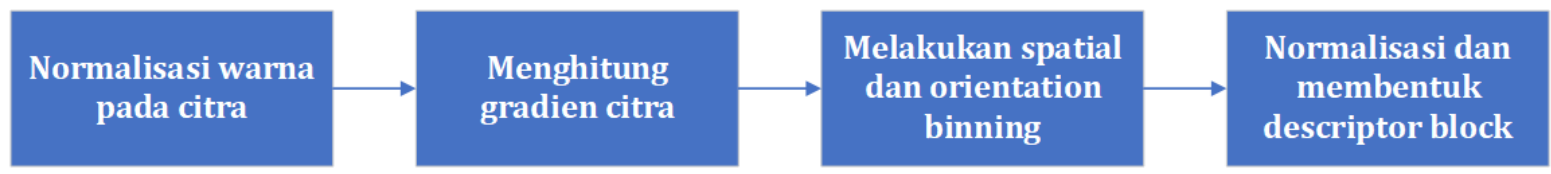

Gambar 4. Tahapan Metode HOG [12]

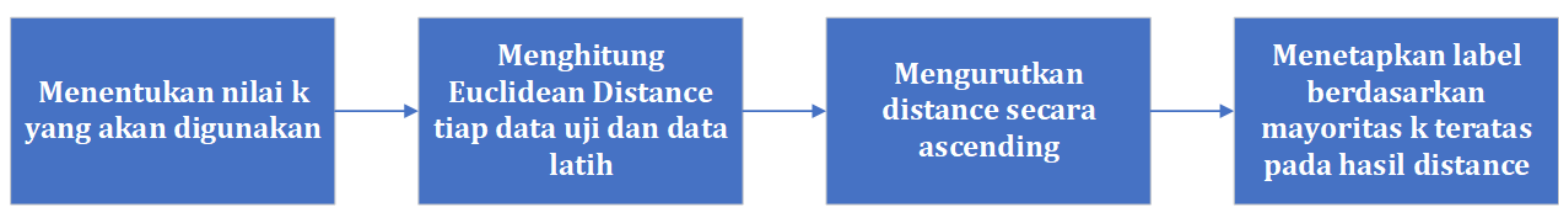

Gambar 5. Tahapan Metode k-NN [13]

\section{HASIL DAN PEMBAHASAN}

Klasifikasi jenis hewan mamalia dilakukan dengan menggunakan fitur HOG berbasis citra saliency. Hasil ekstraksi fitur HOG pada citra saliency dapat dilihat pada Gambar 6. Pengujian terhadap klasifikasi jenis hewan mamalia menggunakan k-NN dilakukan dengan nilai $k$ yang berbeda, yaitu $\mathrm{k}=3, \mathrm{k}=5, \mathrm{k}=7$, dan $\mathrm{k}=9$. Selain itu, pengujian juga dilakukan dengan cityblock dan euclidean distance. Hasil klasifikasi hewan mamalia menggunakan cityblock distance untuk setiap $k$ dapat dilihat pada Tabel 1. Hasil pengujian menggunakan cityblock distance menunjukkan bahwa metode k-NN mampu mengklasifikasi jenis hewan mamalia untuk setiap $k$ yang berbeda. Secara keseluruhan, metode k-NN dengan cityblock distance menunjukkan nilai precision, recall, dan accuracy terbaik pada $\mathrm{k}=9$.

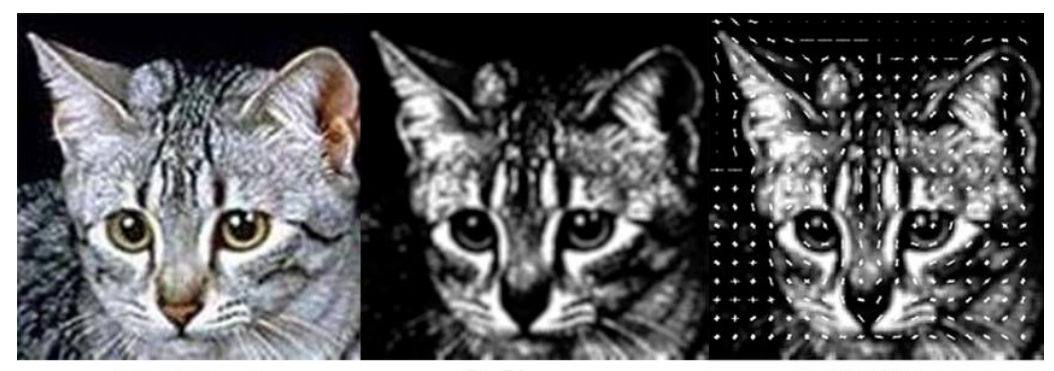

$$
\begin{array}{lll}
\text { Original Saliency } & \text { HOG }
\end{array}
$$

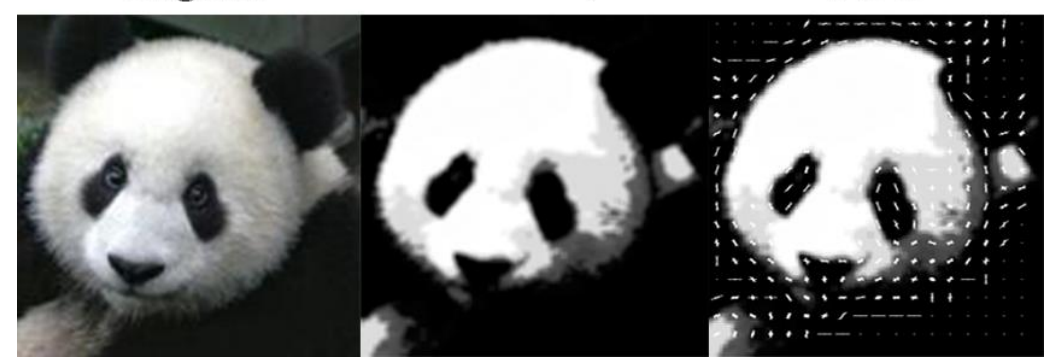

Gambar 6. Visualisasi Ekstraksi Fitur HOG dengan Saliency 
PETIR: Jurnal Pengkajian dan Penerapan Teknik Informatika Vol. 13, No. 1, Maret 2020, P-ISSN 1978-9262, E-ISSN 2655-5018 DOI: https://doi.org/10.33322/petir.v13i1.908

Tabel 2 memperlihatkan hasil klasifikasi hewan mamalia menggunakan euclidean distance untuk setiap $k$. Hasil pengujian menggunakan euclidean distance menunjukkan bahwa metode k-NN tidak terlalu mampu mengklasifikasi jenis hewan mamalia untuk setiap $k$ yang berbeda. Nilai precision terbaik didapatkan pada $\mathrm{k}=5$, sedangkan nilai recall terbaik didapatkan pada $\mathrm{k}=3$, dan nilai accuracy terbaik didapatkan pada k=3 untuk metode k-NN dengan euclidean distance. Hewan mamalia yang belum terklasifikasi dengan baik dengan euclidean distance adalah Anjing, Singa, Babi, dan Domba.

Tabel 1. Hasil klasifikasi hewan mamalia menggunakan cityblock distance

\begin{tabular}{|c|l|c|c|c|c|c|c|c|c|c|c|c|c|}
\hline \multirow{2}{*}{ No } & \multirow{2}{*}{ Kelas } & \multicolumn{4}{|c|}{ Precision } & \multicolumn{4}{|c|}{ Recall } & \multicolumn{4}{|c|}{ Accuracy } \\
\cline { 2 - 14 } & & $\boldsymbol{k}=\mathbf{3}$ & $\boldsymbol{k}=\mathbf{5}$ & $\boldsymbol{k}=\mathbf{7}$ & $\boldsymbol{k}=\mathbf{9}$ & $\boldsymbol{k}=\mathbf{3}$ & $\boldsymbol{k}=\mathbf{5}$ & $\boldsymbol{k}=\mathbf{7}$ & $\boldsymbol{k = 9}$ & $\boldsymbol{k}=\mathbf{3}$ & $\boldsymbol{k}=\mathbf{5}$ & $\boldsymbol{k}=\mathbf{7}$ & $\boldsymbol{k}=\mathbf{9}$ \\
\hline 1 & Beruang & 0.70 & 0.50 & 0.50 & 0.50 & 0.32 & 0.29 & 0.38 & 0.38 & 0.88 & 0.89 & 0.91 & 0.92 \\
\hline 2 & Kucing & 0.60 & 0.60 & 0.60 & 0.70 & 0.86 & 0.86 & 0.86 & 1.00 & 0.97 & 0.97 & 0.97 & 0.98 \\
\hline 3 & Sapi & 0.70 & 0.80 & 0.60 & 0.60 & 0.44 & 0.62 & 0.43 & 0.43 & 0.92 & 0.95 & 0.92 & 0.92 \\
\hline 4 & Rusa & 0.80 & 0.80 & 0.80 & 0.70 & 0.62 & 0.62 & 0.73 & 0.64 & 0.95 & 0.95 & 0.97 & 0.95 \\
\hline 5 & Anjing & 0.60 & 0.60 & 0.50 & 0.60 & 0.86 & 1.00 & 1.00 & 1.00 & 0.97 & 0.97 & 0.97 & 0.97 \\
\hline 6 & Gajah & 0.90 & 1.00 & 0.70 & 0.90 & 0.53 & 0.63 & 0.50 & 0.53 & 0.94 & 0.96 & 0.93 & 0.94 \\
\hline 7 & Singa & 0.30 & 0.30 & 0.50 & 0.50 & 0.50 & 0.75 & 0.83 & 1.00 & 0.93 & 0.95 & 0.96 & 0.97 \\
\hline 8 & Monyet & 0.30 & 0.30 & 0.40 & 0.40 & 0.60 & 0.75 & 0.80 & 0.80 & 0.94 & 0.95 & 0.95 & 0.95 \\
\hline 9 & Tikus & 0.50 & 0.30 & 0.20 & 0.30 & 0.63 & 0.43 & 0.33 & 0.50 & 0.95 & 0.93 & 0.92 & 0.93 \\
\hline 10 & Panda & 0.80 & 1.00 & 1.00 & 1.00 & 1.00 & 1.00 & 1.00 & 1.00 & 0.99 & 1.00 & 1.00 & 1.00 \\
\hline 11 & Babi & 0.30 & 0.20 & 0.50 & 0.30 & 0.75 & 0.67 & 0.63 & 0.60 & 0.95 & 0.94 & 0.95 & 0.94 \\
\hline 12 & Kelinci & 0.50 & 0.40 & 0.50 & 0.50 & 0.63 & 0.67 & 0.63 & 0.71 & 0.95 & 0.95 & 0.95 & 0.95 \\
\hline 13 & Domba & 0.20 & 0.30 & 0.40 & 0.40 & 0.50 & 0.60 & 0.57 & 0.80 & 0.93 & 0.94 & 0.94 & 0.95 \\
\hline 14 & Harimau & 1.00 & 1.00 & 1.00 & 1.00 & 0.53 & 0.43 & 0.38 & 0.38 & 0.94 & 0.92 & 0.89 & 0.89 \\
\hline 15 & Serigala & 0.50 & 0.90 & 0.90 & 1.00 & 0.83 & 0.82 & 0.90 & 0.77 & 0.96 & 0.98 & 0.99 & 0.98 \\
\hline
\end{tabular}

Tabel 2. Hasil klasifikasi hewan mamalia menggunakan euclidean distance

\begin{tabular}{|c|l|l|l|l|l|l|l|l|l|l|l|l|l|}
\hline \multirow{2}{*}{ No } & \multirow{2}{*}{ Kelas } & \multicolumn{4}{|c|}{ Precision } & \multicolumn{4}{|c|}{ Recall } & \multicolumn{4}{|c|}{ Accuracy } \\
\cline { 3 - 14 } & $\boldsymbol{k}=\mathbf{3}$ & $\boldsymbol{k}=\mathbf{5}$ & $\boldsymbol{k}=\mathbf{7}$ & $\boldsymbol{k}=\mathbf{9}$ & $\boldsymbol{k}=\mathbf{3}$ & $\boldsymbol{k}=\mathbf{5}$ & $\boldsymbol{k}=\mathbf{7}$ & $\boldsymbol{k}=\mathbf{9}$ & $\boldsymbol{k}=\mathbf{3}$ & $\boldsymbol{k}=\mathbf{5}$ & $\boldsymbol{k}=\mathbf{7}$ & $\boldsymbol{k}=\boldsymbol{9}$ \\
\hline 1 & Beruang & 0.70 & 0.60 & 0.60 & 0.60 & 0.24 & 0.32 & 0.33 & 0.43 & 0.83 & 0.89 & 0.89 & 0.92 \\
\hline 2 & Kucing & 0.30 & 0.50 & 0.20 & 0.40 & 0.75 & 0.71 & 0.67 & 0.80 & 0.95 & 0.95 & 0.94 & 0.95 \\
\hline 3 & Sapi & 0.70 & 0.40 & 0.40 & 0.40 & 0.64 & 0.57 & 0.67 & 0.67 & 0.95 & 0.94 & 0.95 & 0.95 \\
\hline 4 & Rusa & 0.60 & 0.60 & 0.45 & 0.30 & 0.86 & 0.86 & 0.83 & 0.75 & 0.97 & 0.97 & 0.95 & 0.95 \\
\hline 5 & Anjing & 0.30 & 0.00 & 0.00 & 0.00 & 0.75 & NaN & NaN & NaN & 0.95 & 0.94 & 0.93 & 0.93 \\
\hline 6 & Gajah & 0.90 & 0.90 & 0.70 & 0.70 & 1.00 & 0.41 & 0.33 & 0.29 & 0.99 & 0.91 & 0.89 & 0.86 \\
\hline 7 & Singa & 0.20 & 0.00 & 0.10 & 0.00 & 1.00 & NaN & 1.00 & NaN & 0.95 & 0.94 & 0.94 & 0.93 \\
\hline 8 & Monyet & 0.30 & 0.40 & 0.20 & 0.20 & 0.75 & 1.00 & 0.67 & 0.67 & 0.95 & 0.96 & 0.94 & 0.94 \\
\hline 9 & Tikus & 0.20 & 0.30 & 0.40 & 0.30 & 0.40 & 0.60 & 0.67 & 1.00 & 0.93 & 0.94 & 0.95 & 0.95 \\
\hline 10 & Panda & 0.40 & 0.40 & 0.40 & 0.30 & 1.00 & 1.00 & 1.00 & 1.00 & 0.96 & 0.96 & 0.96 & 0.95 \\
\hline 11 & Babi & 0.10 & 0.10 & 0.10 & 0.00 & 0.50 & 1.00 & 0.33 & NaN & 0.93 & 0.94 & 0.93 & 0.93 \\
\hline 12 & Kelinci & 0.20 & 0.20 & 0.20 & 0.20 & 1.00 & 1.00 & 0.67 & 0.67 & 0.95 & 0.95 & 0.94 & 0.94 \\
\hline 13 & Domba & 0.00 & 0.20 & 0.00 & 0.00 & NaN & 1.00 & NaN & NaN & 0.93 & 0.95 & 0.93 & 0.93 \\
\hline 14 & Harimau & 1.00 & 1.00 & 1.00 & 1.00 & 0.24 & 0.17 & 0.16 & 0.14 & 0.79 & 0.68 & 0.64 & 0.60 \\
\hline 15 & Serigala & 0.30 & 0.60 & 0.50 & 0.60 & 0.60 & 0.50 & 0.42 & 0.40 & 0.94 & 0.93 & 0.92 & 0.91 \\
\hline
\end{tabular}

Secara keseluruhan, metode k-NN yang menggunakan cityblock distance lebih baik daripada euclidean distance dalam klasifikasi jenis hewan mamalia. 
PETIR: Jurnal Pengkajian dan Penerapan Teknik Informatika Vol. 13, No. 1, Maret 2020, P-ISSN 1978-9262, E-ISSN 2655-5018 DOI: https://doi.org/10.33322/petir.v13i1.908

\section{KESIMPULAN DAN SARAN}

Berdasarkan hasil pengujian dapat disimpulkan bahwa metode HOG berbasis saliency mampu mengekstraksi fitur pada wajah hewan mamalia tampak depan dengan baik. Metode k-NN sebagai metode klasifikasi mampu mengklasifikasi jenis hewan mamalia untuk setiap $k$ dengan tingkat precision, recall, dan accuracy yang berbeda. Metode k-NN dengan cityblock distance lebih baik daripada euclidean distance pada klasifikasi jenis hewan mamalia dengan $\mathrm{k}=9$. Hewan mamalia yang dapat dikenali dengan baik adalah Harimau. Sedangkan hewan mamalia yang tidak dapat dikenali dengan baik adalah Domba.

\section{DAFTAR PUSTAKA}

[1] M. N. Alli and S. Viriri, "Animal identification based on footprint recognition," IEEE Int. Conf. Adapt. Sci. Technol. ICAST, 2013.

[2] S. Taheri and Ö. Toygar, "Animal classification using facial images with score-level fusion," IET Comput. Vis., vol. 12, no. 5, pp. 679-685, 2018.

[3] M. E. Al Rivan and Y. Yohannes, "Klasifikasi Mamalia Berdasarkan Bentuk Wajah Dengan K-NN Menggunakan Fitur CAS Dan HOG,” J. Tek. Inform. dan Sist. Inf., vol. 5, no. 2, pp. 173-180, 2019.

[4] Y. Yohannes, Y. P. Sari, and I. Feristyani, "Klasifikasi Wajah Hewan Mamalia Tampak Depan Menggunakan k-Nearest Neighbor Dengan Ekstraksi Fitur HOG," J. Tek. Inform. dan Sist. Inf., vol. 5, no. 1, pp. 84-97, 2019.

[5] Z. Cao, J. C. Principe, B. Ouyang, F. Dalgleish, and A. Vuorenkoski, "Marine Animal Classification Using Combined CNN and Hand-designed Image Features," Ocean. 2015 MTS/IEEE Washingt., pp. 2-7, 2015.

[6] S. D. Cahyaningtyas, "Pengenalan Wajah Menggunakan Metode Ekstraksi Fitur Local Binary Pattern Berdasarkan Metode K-Nearest Neighbor," Tek. Inform. Univ. Dian Nuswantoro, 2016.

[7] F. Liantoni and H. Nugroho, "Klasifikasi Daun Herbal Menggunakan Metode Naïve Bayes Classifier Dan K- Nearest Neighbor,” J. Simantec, vol. 5, no. 1, pp. 9-16, 2015.

[8] H. Wijayanto, "Klasifikasi Batik Menggunakan Metode K-Nearest Neighbour Berdasarkan Gray Level Co-Occurrence Matrices (GLCM),” Tek. Inform. FIK UDINUS, 2015.

[9] F. Fandiansyah, J. Y. Sari, and I. P. Ningrum, "Pengenalan Wajah Menggunakan Metode Linear Discriminant Analysis Dan K Nearest Neighbor,” J. Inform., vol. 11, no. 2, pp. 48-59, 2017.

[10] M. M. Cheng, N. J. Mitra, X. Huang, P. H. S. Torr, and S. M. Hu, "Global contrast based salient region detection," IEEE Trans. Pattern Anal. Mach. Intell., vol. 37, no. 3, pp. 569-582, 2015.

[11] Z. Si and S. Zhu, "Learning Hybrid Image Templates (HIT) by Information Projection," IEEE Trans. Pattern Anal. Mach. Intell., pp. 1354-1367, 2012.

[12] N. Dalal and B. Triggs, "Histograms of oriented gradients for human detection," in Proceedings - 2005 IEEE Computer Society Conference on Computer Vision and Pattern Recognition, CVPR 2005, 2005, vol. I, pp. 886-893.

[13] J. P. Jose, P. Poornima, and K. M. Kumar, "A novel method for color face recognition using KNN classifier,” 2012 Int. Conf. Comput. Commun. Appl. ICCCA 2012, 2012. 